\title{
Competition among spatial cues in a naturalistic food-carrying task
}

\author{
BRETT M. GIBSON and SARA J. SHETTLEWORTH \\ University of Toronto, Toronto, Ontario, Canada
}

\begin{abstract}
Rats collected nuts from a container in a large arena in four experiments testing how learning about a beacon or cue at a goal interacts with learning about other spatial cues (place learning). Place learning was quick, with little evidence of competition from the beacon (Experiments 1 and 2). Rats trained to approach a beacon regardless of its location were subsequently impaired when the well-learnedbeacon was removed and other spatial cues identified the location of the goal (Experiment 3). The competition between beacon and place cues reflected learned irrelevance for place cues (Experiment 4). The findings differ from those of some studies of associativeinteractions between cue and place learning in other paradigms.
\end{abstract}

The natural world provides animals with a number of potentially redundant kinds of spatial information, including beacons (cues) at goals, distal landmarks, overall spatial geometry, self-generated cues from dead reckoning, and learned motor routines (Gallistel, 1990; Shettleworth, 1998). How do different cues such as these interact during learning and performance of spatial tasks? The cognitive sciences have proposed three somewhat conflicting answers to this question: Spatial learning is a matter of cognitive maps, of separable but parallel memory systems, and of competitive interactions among simple associations.

Cue competition effects have been reported in simple associative learning when two or more conditioned stimuli (CSs) predict the occurrence of an event (unconditioned stimulus, US), as in Pavlovian conditioning. Historically, cue competition has been examined with such procedures as blocking (Kamin, 1969), overshadowing (Pavlov, 1927), and relative stimulus validity (Wagner, Logan, Haberlandt, \& Price, 1968), using relatively simple stimuli. Recently, however, researchers interested in navigation have used traditional cue competition procedures to examine how spatial cues interact during learning (see Cheng \& Spetch, 1998). For example, beacons

Some of the results of Experiments 1 and 2 were reported at the Conference on Comparative Cognition, Melbourne, FL, March 2001, and at the Gregynog Conference on Associative Learning, Gregynog, Wales, April 2001. This research was supported by a research grant to the second author from the Natural Sciences and Engineering Research Council of Canada. We thank Andrew Gristock and Loull Silver for animal care, Jennifer Barker, Amy Dalton, Lori Grappone, Ben David Jee, Noam Miller, and Loull Silver for testing the animals, and Noam Miller for indispensible help with data analysis. B.M.G. is now at the University of New Hampshire. Correspondence may be directed to S. J. Shettleworth, Department of Psychology, University of Toronto, 100 St. George Street, Toronto, ON, M5S 3G3 Canada (e-mail: shettle@psych.utoronto.ca).

— Accepted by previous editorial team of Ralph R. Miller can overshadow and block distal landmarks. Rats for which a previously trained beacon identified the fixed location of a dry platform in a water maze were less likely to locate a hidden platform if that beacon had previously indicated a platform's location than if it had not (Redhead, Roberts, Good, \& Pearce, 1997; see also Roberts \& Pearce, 1999). Similarly, in a radial maze, cues on the arms block cues identifying the locations of the rewarded arms relative to the room, and vice versa (Diez-Chamizo, Sterio, \& Mackintosh, 1985). Overshadowing between beacons and landmarks has also been shown in both the water maze and the radial maze (Diez-Chamizo et al., 1985; March, Chamizo, \& Mackintosh, 1992; Pearce, Roberts, \& Good, 1998; Redhead et al., 1997).

Often contrasted with the idea that spatial learning works like simple associative learning is the notion that animals form unified cognitive maps of the environment (O’Keefe \& Nadel, 1978; Tolman, 1948). Cognitive mapping seems to imply that multiple redundant sources of spatial information are all encoded with little, if any, competition. Evidence of overshadowing and blocking in spatial learning has therefore been taken as contrary to the cognitive mapping hypothesis (for discussions, see Biegler \& Morris, 1999; Mackintosh, 2002). A better substantiated alternative to the idea that spatial cues compete during learning is the suggestion, based on neuropsychologicaldata, that spatial navigation is supported by several separable learning and memory systems that acquire different kinds of information somewhat independently and in parallel (McDonald \& White, 1993; White $\&$ McDonald, 2002). Evidence for this idea consists primarily of neuroanatomical dissociations of learning and/ or performance on tasks dependent on different systems. For example, McDonald and White (1994; see also Packard \& McGaugh, 1992) compared intact rats with rats with hippocampal or dorsal striatal lesions on acquisition in a water maze with the platform visible and in the same place throughout training. Hippocampal-lesioned 
rats learned to approach the visible platform but did not learn its location relative to landmarks, whereas the reverse was true of the rats with striatal lesions. It is noteworthy that in this and many related examples (for a review, see White \& McDonald, 2002), the same behavioral paradigm as that used to test for associative interactions among beacons and more global spatial cues is said to tap more than one parallel memory system.

Ethological studies of rodents retrieving food or pups to their nests also suggest that different kinds of spatial information are acquired in parallel, rather than competitively. For example, when mother mice retrieve their pups, at first efficient orientation back to the nest is controlled by dead reckoning, but after many trips landmarks take control (Alyan \& Jander, 1994). Such findings suggest that dead reckoning may not compete with landmark learning, but more formal tests of cue competition remain to be done in this situation. The results of some studies indicate that when rats or hamsters search for food and then carry it back to a home base, they acquire a number of kinds of spatial information in parallel and use them in a hierarchical manner. For example, Whishaw and Tomie (1997) placed a black box (a beacon) over the entrance to rats' home base. This home base could also be found using landmarks and dead reckoning. When the home base was moved every few trials, the rats often went first to its old location, as defined by landmarks in the room, before heading to the new home location. In other words, although the beacon and/or dead reckoning were most consistently associated with the home, the rats learned its location relative to landmarks at the same time (for other examples, see Etienne, Berlie, Georgakopoulos, \& Maurer, 1998). Thus, in this situation, beacon learning does not appear to compete with landmark learning. Again, more formal tests remain to be done-for example, by comparing the amount learned about a beacon when the amount of prior training with potentially competing cues is varied.

In summary, there is conflicting evidence regarding whether learning about beacons competes with learning about other spatial cues. Moreover, much of the support for competition comes from experiments in which the aversively motivated Morris water-maze task was used. Different kinds of spatial tasks may unexpectedly produce different kinds of results even though the attempt is to address the same spatial learning. For example, disorientation does not affect the rate of acquisition in the water maze, but it slows learning in a dry land, foodrewarded version of the same task (Gibson, Shettleworth, \& McDonald, 2001). Although competition between different kinds of spatial cues has been assessed, to some extent, with paradigms other than the water maze (e.g., Diez-Chamizo et al., 1985), it is important to examine how multiple cues interact when a broader range of paradigms is used. We employed a naturalistic foraging test in which rats carried food from a large arena into a fixed refuge (Figure 1), to test whether beacon and place cues are learned in a competitive manner.

\section{EXPERIMENT 1A}

When a rat finds large pieces of food in an exposed place, the rat carries them to safety, rather than eating them on the spot (Whishaw \& Tomie, 1989). Thus, rats provided with a refuge of some kind spontaneously travel to and fro collecting food and eating it. The motivational control of this food-carrying behavior, the learning involved in it, and the neural basis of that learning have been analyzed extensively by Whishaw and his colleagues (Maaswinkel \& Whishaw, 1999; Whishaw \& Gorney, 1999; Whishaw \& Tomie, 1997; see also Phelps \& Roberts, 1989). Like Etienne and her colleagues (Etienne et al., 1998) in their studies of hamsters' food hoarding, they have focused on how an animal finds its way back to its refuge, by measuring the directness of homeward paths when cues available during the outward and/or homeward journey are manipulated. In contrast to previous studies of food carrying, the experiments reported in this article focus on what animals learn about the location of food when the refuge is always in the same place. Thus, the primary data are measures of the accuracy of orientation on the outward, rather than on the homeward, journey. Experiments $1 \mathrm{~A}$ and $1 \mathrm{~B}$ were exploratory in nature and examined whether rats would learn about both the place where food is found in a large room and a beacon at the food. A distinctive object holding food, functioning as a beacon, was in the same location for several sessions (Experiment 1A) and then was moved for every session (Experiment 1B). The extent to which the rats had learned where the food was with respect to spatial cues other than the beacon was assessed by seeing where the rats went when the beacon and the food were removed. To eliminate possible odor trails between the food and the refuge, the floor was washed before these place tests, as well as at comparable points in control sessions without place tests.

Any object or feature of a surface that maintains a stable geometric relationship with a goal across time can be used as a landmark indicating the place of reward. In the present experiments, the fixed features of the room (e.g., corners, speakers, doors, camera, window) could function as landmarks. The location of the food relative to the overall geometry of the room could also be used, as could a memory of the path taken to the food. All of these defined the place where food was found in the room. An animal learning the location of food in the natural environment encounters a comparable array of spatial cues. The beacon(s) used during experimentation also indicate the location of the goal but differ from the global place cues mentioned above because of their proximity to the goal. In effect, approaching an object at a goal such as the beacons in the present experiments is no different from the goal tracking that results from Pavlovian conditioning. Rather than remembering vector-like information and triangulating on distant objects, computationally approaching a cue at a goal requires only a simple hill-climbing process (Gallistel, 1990; Shettle- 


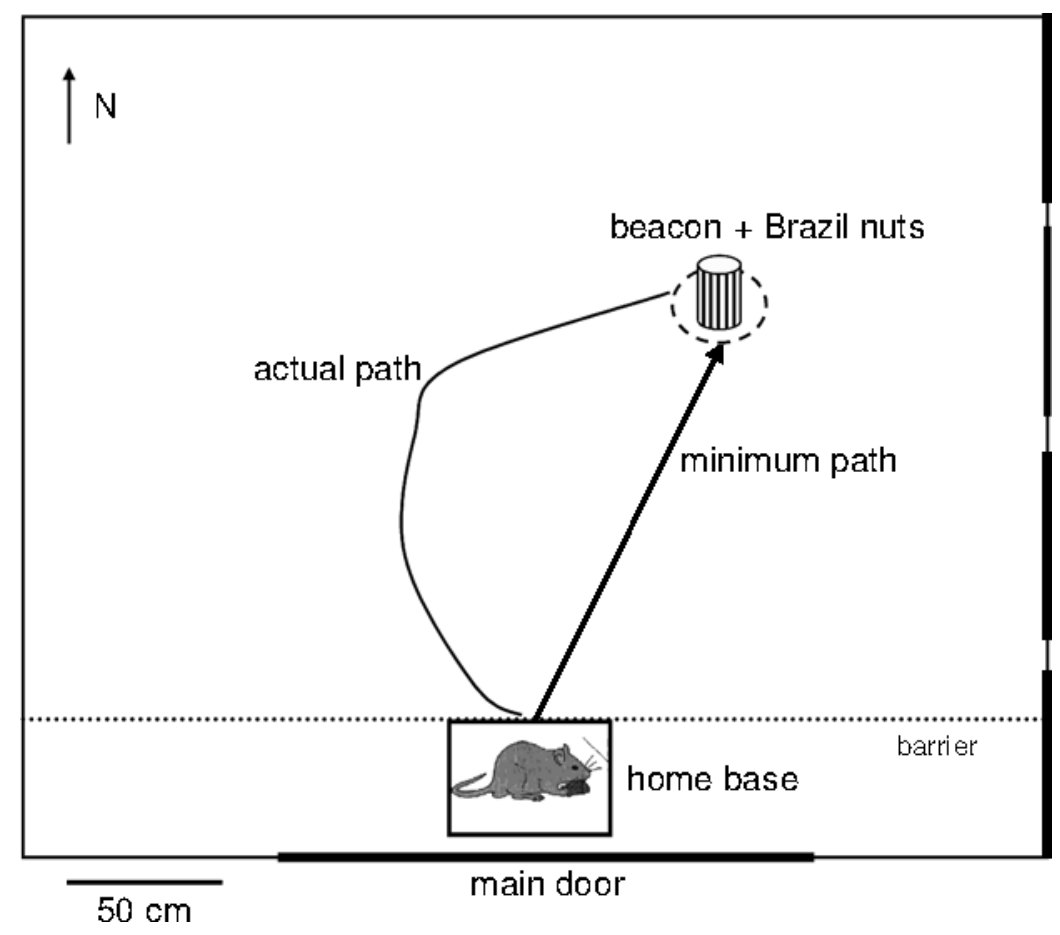

Figure 1. Diagram of the testing area, indicating the primary features of the room and the behavioral measures used. The large sliding main door through which the experimenter and the animals entered and withdrew from the room is indicated by a large bold line on the bottom of the diagram. The home cage was located in a gap between the south wall of the room and a low barrier (see the text). The east wall of the room was composed of textured panels (large dashed line on the east wall of the diagram); large black recessed grooves were formed by adjacent light gray sections of the panels. The index of path length analyzed throughout the article is the difference between the actual path and the minimum path. The beacon, rat, and home box are not to scale.

worth, 1998). Consistent with this idea, cues from beacons may be processed by different neural systems than global spatial cues (White \& McDonald, 2002).

\section{Method}

Animals. Six experimentally naive male Long-Evans rats from Charles River, Canada, were used. They were housed individually in a vivarium that was kept on a 12:12-h reversed dark:light schedule and were tested during the dark phase. Each home cage contained nesting paper and an opaque plastic tube big enough for a rat to enter. The rats were 10 weeks old and weighed $352-386 \mathrm{~g}$ at the start of the experiment. All the rats had free access to water and were fed a diet of rat chow that maintained them at $85 \%$ of their adlib weights.

Experimental room and global place cues. The experiment was conducted in a room that measured $222 \mathrm{~cm}$ on its north-south $(\mathrm{N}-\mathrm{S})$ axis and $357 \mathrm{~cm}$ on its east-west (E-W) axis. Three walls were painted beige. The west wall had a gray cloth surface. The concrete floor of the room was texturized. The sides of a closet in the NW corner protruded $41 \mathrm{~cm}$ to the south and $110 \mathrm{~cm}$ to the east into the room. Two banks of florescent lights running to the north and south in the ceiling provided illumination. A 46-cm-tall barrier located $35 \mathrm{~cm}$ north of the south wall extended across the long axis of the room. The rat had access to the space between the barrier and the north wall through a 12-cm-diameter hole in the center and at the bottom of the barrier. An opaque plastic home box $(26 \mathrm{~cm}$ long $\times 27 \mathrm{~cm}$ wide $\times 21 \mathrm{~cm}$ high) with bedding material on the floor was attached to the south face of the barrier over the hole. A guillotine door could be opened and closed over the hole by pulling a line outside the room. White noise was filtered into the room from four speakers positioned in the ceiling and, to the human ear, provided an even level of sound. A video camera suspended from the center of the ceiling was connected to videotaping and digital tracking equipment in the observation area. During sessions, the experimenter sat in this observation area and watched the rat on a video monitor. The experimenter could move between the experimental room and the observation area through a large horizontally sliding door located in the south wall of the experimental room. This door held a 50-cm-diameter hemispherical plastic observation window that protruded into the testing room. The window was blacked out throughout these experiments.

Beacons. Two cylindrical beacons were used. The pretraining beacon was a shallow dish $(2 \mathrm{~cm}$ tall, $7.6 \mathrm{~cm}$ diameter $)$ made of white PVC. The experimental beacon was a 7.6-cm-diameter PVC cylinder that stood $7 \mathrm{~cm}$ tall and had vertical black-and-white stripes approximately $2 \mathrm{~cm}$ wide on the sides. A dish $3 \mathrm{~cm}$ deep inside the top end held approximately 70 pieces of Brazil nuts that were cut into pieces approximately $1 \mathrm{~cm}^{3}$ in size and weighing $1 \mathrm{gm}$. The bottoms of the beacons were weighted to prevent the rats from moving them.

Beacon locations. A virtual square grid overlaid the floor of the experimental room. Points formed by the intersection of the lines of the grid were separated by $30 \mathrm{~cm}$ in either the $\mathrm{N}-\mathrm{S}$ or the $\mathrm{E}-\mathrm{W}$ direc- 
tion. These were marked by circles lightly drawn on the floor. Fortyeight of these points were selected as locations in which a beacon could be placed during a session. Each location was at least $60 \mathrm{~cm}$ from any wall and at least $70 \mathrm{~cm}$ from the entrance to the home. The room was divided into four quadrants, corresponding with the NE, NW, SE, and $\mathrm{SW}$, and 12 beacon locations were included in each quadrant.

Measures and analysis. A rat made a trip when it departed the home box through the guillotine door, crossed into a 30-cm-diameter circular virtual goal zone centered on the cylinder, and then returned to the home box. A virtual home zone $30 \mathrm{~cm}$ in diameter was centered over the middle of the guillotine door. The position of the rat was recorded as it moved through the room, using tracking software (Noldus Information Technology, Sterling, VA). The total length of an outward path was determined by calculating the total distance the rat moved between departing the center of the home zone and crossing the perimeter of the goal zone. Difference scores were used to standardize the data across conditions in which the beacon was at different distances from the home. The straight-line distance between the center of the home and the edge of the goal zone was subtracted from the total distance the rat traveled before reaching the goal zone (see Figure 1). Throughout this article, this measure is usually referred to simply as outward path (or trip) length. When an animal moves straight to the food its value is zero. Path lengths were log transformed to maintain normality, and the transformed data were subjected to an analysis of variance (ANOVA). Throughout this article, results are reported as statistically significant if $p<.05$. Although the analyses were performed with $\log$ transformed data, all the figures depict untransformed values. The figures show medians, which were more representative of typical performance than means would be, because means could be greatly increased by the occasional rat's taking a path many meters long on trials when most rats went straight to the food.

The rats' headings when leaving the home zone, relative to a line straight to the food, were analyzed in a way similar to that for path lengths. However, in the present experiments, outward heading was not very informative. The range within which headings could vary was constrained, because the rats started from the edge of a rectangular space and also because, once they learned that food was never near the edge from which they started, headings varied only within about $100^{\circ}$. As one would predict on the basis of these considerations, statistical effects on headings were generally weaker than those on path lengths but were consistent with them. Therefore, heading data are not reported.

Pretraining. Before pretraining, each rat was handled $10 \mathrm{~min}$ a day for 3 days and was given a few Brazil nut pieces to eat in its home cage. The pretraining beacon was stocked with pieces of nuts and was placed $30 \mathrm{~cm}$ directly north of the guillotine door. A pretraining session began when a rat was transferred to the home base in the experimental room. The rat was allowed a maximum of 15 min to make six trips between the home box and the beacon. Each rat experienced one session of pretraining each day for 4 days. The procedures were identical for Days 2-4, except that the food was $1 \mathrm{~m}$ directly north of the door on Day 2 . On Day 3 , the food was $200 \mathrm{~cm}$ and $28^{\circ} \mathrm{NW}$ of the entrance (angles are measured with respect to a line perpendicular to the south wall from the center of the home zone). On Day 4, it was $220 \mathrm{~cm}$ and $32^{\circ} \mathrm{NE}$. If a rat did not leave the home base on the first session of pretraining, that session was repeated the next day. Rats that did not come out on that session were replaced with other rats. Fewer than $10 \%$ of the animals in all four of the present experiments were replacement rats.

Acquisition. The striped cylinder was stocked with approximately 70 nut pieces and was placed $25^{\circ} \mathrm{NE}$ and $212 \mathrm{~cm}$ from the center of the home zone. The floor was wiped with a sponge mop made damp with water and a mild cleaning solution. The rat was allowed to make five trips, and then the guillotine door was closed, blocking the rat into the home box. During the ensuing 3 min intertrial interval (ITI), the experimenter mopped the entire surface of the floor. The guillotine door was then reopened, and the rat was allowed to make one final trip. The session ended following the sixth trip. Each rat encountered seven daily six-trip sessions. Occasionally, some rats stopped and ate at the beacon. The rat was encouraged by the experimenter to return home under these circumstances by first shaking a set of keys near the door and, if that failed, entering the room and directing the rat back to the home box.

Place tests. A place test was given on Days 2 and 6 of acquisition. On these days, the first five trips proceeded as described above. However, the feeder and the nuts were removed during the ITI before the start of the sixth trip. The rat then was released into the room, and its movement was recorded for $20 \mathrm{sec}$ after it first departed the home base. After $20 \mathrm{sec}$ had passed, the experimenter entered the room and the rat returned to the home box to end the trial. The path lengths entered into the analyses were the path lengths to the goal zone if the rat entered the goal zone during the 20 -sec trial and the total path length within $20 \mathrm{sec}$ otherwise.

\section{Results and Discussion}

The rats' general behavior was like that of rats in previous studies of food carrying (e.g., Whishaw, Coles, \& Bellerive, 1995; Whishaw \& Tomie, 1989). By the end of pretraining, most of the rats came out promptly and traveled unhesitatingly all over the room. Once they had collected a piece of nut from the top of the beacon, the rats ran straight back to the home base. Some rats occasionally left a few nut fragments in the home box in early sessions, but in general, they ate each nut immediately in the home box and did not accumulate a hoard.

When the beacon with food remained in the same place for 7 days, the rats' paths to it quickly became almost maximally straight and direct (Figure 2). An overall ANOVA on the transformed path lengths for Trips $1-5$ revealed significant effects of days and trips, and a significant interaction $[F(6,30)=8.42, F(4,20)=12.93$, and $F(24,120)=$ 3.22 , respectively]. Post hoc comparisons using Fisher's least significant differences test (LSD) showed that Day 1 differed from all other days and that Trip 1 differed from all subsequent trips. Figure 2 suggests that confining the rats to the home box, lengthening the ITI, and washing the floor before the sixth daily trip disrupted their normally straight trips. To determine whether removing the beacon and the food had an effect on path length scores during place testing, the difference between the path length on Trip 5 and that on Trip 6 was computed for all days. This measure then was log transformed and subjected to an ANOVA. There was no significant effect of days $[F(6,30)<1]$. Thus, the disruptive effect of confining the rat before the last trip was no greater when the beacon had been removed than when it was present, suggesting that the rats had learned where in the room the food was usually located.

Corresponding to the path length measure, the rats were just as likely to enter the goal zone during a training trial as during a place test. The rats entered the goal zone on 11 of 12 occasions ( 6 rats measured across 2 days of training) during the first $20 \mathrm{sec}$ of the final trip (Trip 6) on the day of acquisition before each place test. The rats entered the goal zone during 12 of 12 place tests (again, 6 rats tested on two occasions) when the landmark was removed. 


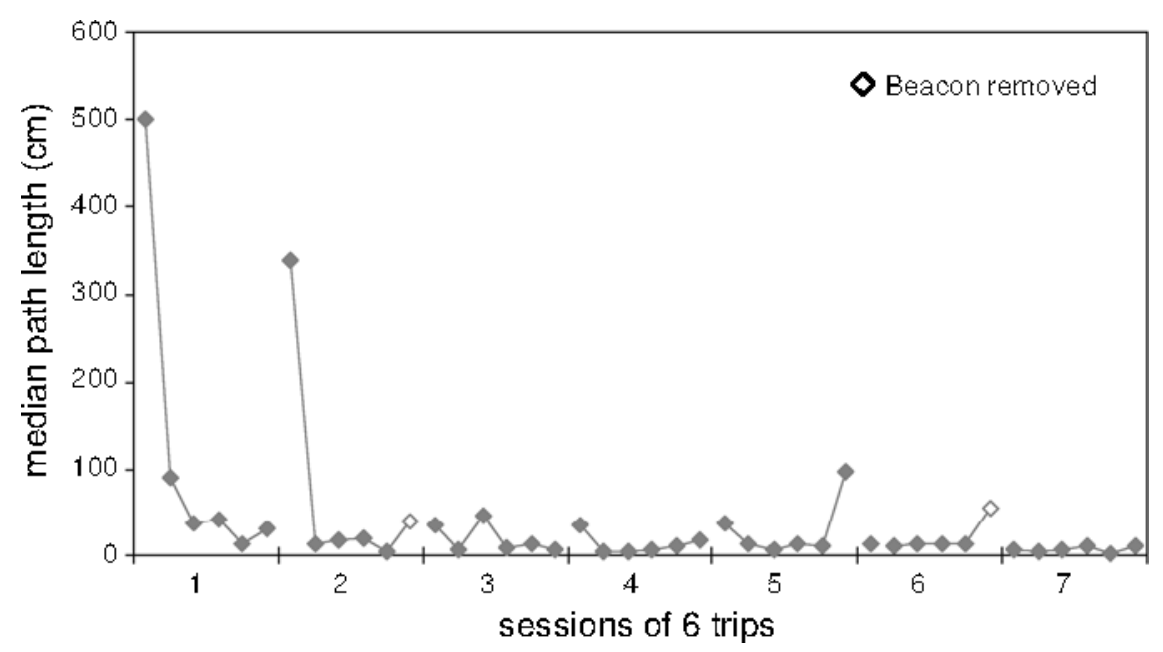

Figure 2. Median path lengths on each trip for the 6 rats in Experiment 1A. Open symbols indicate place tests, when the beacon was removed.

\section{EXPERIMENT 1B}

\section{Method}

Animals and test environment. The rats were the same as those in the previous experiment, maintained in the same way. Testing was conducted in the same room.

Acquisition. This experiment began immediately after Experiment 1A. The procedures were identical to those described for Experiment $1 \mathrm{~A}$, except that the cylinder was moved to a different location at the beginning of each session. Each rat experienced 4 days of acquisition, followed by a 5 th day in which a place test was given on Trip 6. The combination of 4 days of training followed by a day with a place test constituted one block. There were three such blocks.

\section{Results and Discussion}

When food was in a new place each day, the rats tended to go first toward the place where food had been the day before, despite the fact that the beacon was in plain view in another place. Thus, the paths were long at the beginning of each of the early sessions. Performance improved markedly within each session, however (Figure 3). Eventually, the rats went directly toward the beacon on the first daily trip, indicating that their failure to do so earlier did not reflect an inability to see it from the home base. An ANOVA on the transformed path lengths for Trips 1-5 (the trips reinforced on every day) revealed significant effects of both blocks and trips, but their interaction was only marginally significant $[F(2,10)=15.85, F(4,20)=11.18$, and $F(8,40)=2.00, p=.071$, respectively $]$. Trip 1 differed significantly from all other trips, and Trip 2 differed from Trips 4 and 5; the first block of 5 days differed significantly from the subsequent two blocks (Fisher's LSD tests).

Even while the rats tracked the beacon, they were learning about its location in the room. For the three blocks of sessions, we compared Trip 6 with Trip 5 on the day of the place test to those trips on the preceding day in a blocks $\times$ days $\times$ trips ANOVA on the transformed path lengths. The effect of blocks $(F<1.0)$ and trips $[F(1,5)=4.40]$ and the blocks $\times$ trips interaction
$(F<1.0)$ were not significant. The effect of days was marginally significant $[F(1,5)=6.14, p=.056]$. Most important, the blocks $\times$ days and trips $\times$ days interactions were highly significant $[F(2,10)=7.85$ and $F(1,5)=$ 27.25 , respectively]. Fisher's LSD tests showed that the day of the place test did not differ from the preceding day in the first block, whereas it did differ in the second and third blocks. As in Experiment 1A, the rats were just as likely to enter the goal zone during training as during the place tests. The rats entered the goal zone during Trip 6 on the day before a place test on 17 of 18 occasions. Likewise, on 14 of 18 trials, the rats entered the goal zone during the place test when the feeder was absent. The rats were virtually unaffected by the removal of the beacon in the first place test, but later their paths were longer when it was absent (Figure 3).

Experiments $1 \mathrm{~A}$ and $1 \mathrm{~B}$ show that both the beacon and the place cues controlled navigation to a goal in our situation. This makes the food-carrying task an excellent one for further investigating how a beacon and global place cues interact during spatial learning. During the last two place tests of Experiment $1 \mathrm{~B}$, the paths to the goal zone were longer when the beacon was absent, suggesting that the more valid beacon may have reduced place learning. However, the increase in path length during these trips may have been due to the effects of repeated unrewarded probe testing. Experiments $1 \mathrm{~A}$ and $1 \mathrm{~B}$ lacked comparison groups that were trained without beacons, so any assessment of competition is somewhat limited. In each of Experiments $2-4$, we compared separate groups of rats that had different experiences with beacons and places to test more directly for competition between these classes of cues.

\section{EXPERIMENT 2}

Pearce and his colleagues (Redhead et al., 1997) have examined how place and beacon cues interact when rats learn the location of a dry platform in a water maze. 


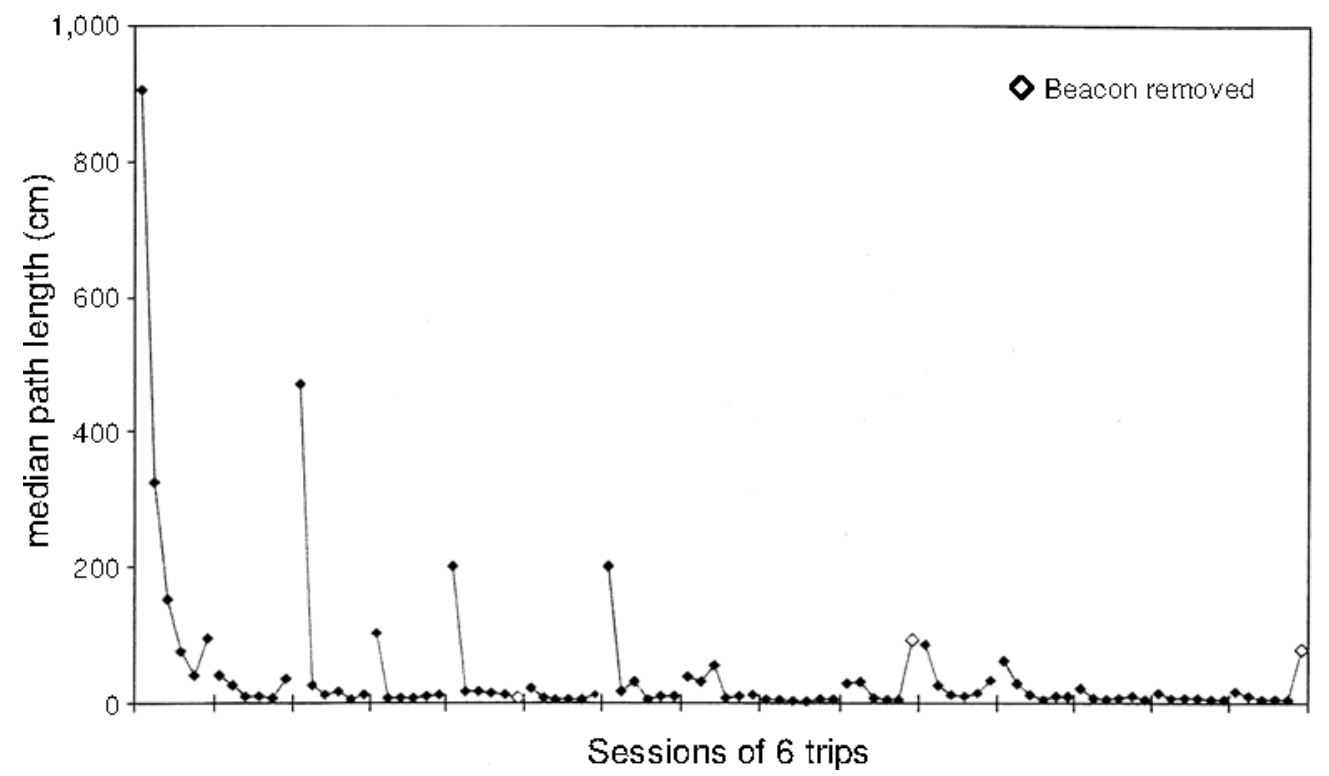

Figure 3. Median path lengths on each trip for the 6 rats in Experiment 1B. Open symbols indicate place tests, when the beacon was removed.

They compared two groups of rats that always found the dry platform in the same location in a pool with two beacons (Experiment 3 in Redhead et al., 1997). For one group, the platform was always marked by the same distinctive beacon so that both place and beacon cues could be used, whereas for the other group the two beacons were identical so that only place cues could be used. In a test with both beacons removed, the group for which both place and beacon were relevant had more difficulty finding the location of a hidden platform than did the group trained with the ambiguous beacon, suggesting that beacon learning detracted from place learning when both were relevant.

In Experiment 2, we used an approach similar to that of Redhead et al. (1997) to see whether a beacon would compete with global place cues in our foraging situation (see Table 1). In Phase 1 (acquisition; see Table 1), two groups of rats always found food in the same place in the room. Two different beacons were always present, the striped cylinder and a gray inverted cone on a cylindrical base. For Group Stable, the same beacon in the same place always held food. For Group Varied, sometimes the cylinder occupied the rewarded place, and sometimes the cone did. Thus, a particular place in the room was $100 \%$ associated with food for both groups, but the beacon also perfectly predicted the location of food for Group Stable. For Group Varied, the relative validity (Wagner et al., 1968) of place cues was greater because the identity of the food-containing beacon varied. Whether beacon cues and place cues compete for learning in some way or for control of performance, rats with a stable beacon should go more directly to the food during acquisition than do rats with a varied beacon. Tests without the beacon were conducted to reveal the effect of the relative validity of place cues. As a further test, in a second part of the experiment, the locations with and without food were reversed, and two more place tests were given. For Group Stable, the same beacon held the food as in the first phase. The food-containing beacon continued to switch unpredictably between cylinder and cone for Group Varied. Rats in Group Stable should begin to approach the old beacon in the formerly unrewarded place more quickly

Table 1

Design of Experiment 2

\begin{tabular}{llclc}
\hline & \multicolumn{3}{c}{ Phase of the Experiment } \\
\cline { 2 - 5 } Group & \multicolumn{1}{c}{ Acquisition* } & Place Testing $\dagger$ & \multicolumn{1}{c}{ Reversal $\$$} & Place Testing $\dagger$ \\
\hline Stable & B1P1+/B2P2 $^{0}$ & P1 vs. P2 & B1P10/B2P2 & P1 vs. P2 \\
Varied & B1P1+/B2P20/B2P1+/B1P2 $^{+}$ & P1 vs. P2 & B1P10/B2P2+/B2P10/B1P2+ & P1 vs. P2* \\
\hline
\end{tabular}

* $\mathrm{B} 1$ and $\mathrm{B} 2$, two different beacons; $\mathrm{P} 1$ and $\mathrm{P} 2$, two rewarded places. The striped cylinder and the gray cone served as either B1 or B2 in a counterbalanced manner. Superscript + and 0 signify reward and nonreward, respectively, in the beacon. Four sessions of five trips. †Trip 5 only; Trips 1-4 same as in preceding phase. Two sessions. ${ }^{\ddagger}$ Four sessions of five trips. 
than rats in Group Varied because, in Phase 1, for them the beacon was a better predictor of food and place was a relatively worse one.

\section{Method}

Animals. Twenty male Long-Evans rats 10-16 weeks old and weighing 264-399 g at the start of testing were used. Five rats in Group Stable and 6 in Group Varied had previously been trained with Froot Loop rewards to enter a specific arm of a radial maze that was located in another room. The other rats were experimentally naive. The rats were maintained at $85 \%$ of their ad-lib body weights, as described previously. All the rats were handled and then randomly assigned to either Group Stable $(n=10)$ or Group Varied $(n=10)$. Two additional rats were trained in Group Stable, but unlike any other rats in the present experiments, they persistently approached the beacons by running along the edge of the room, so that their paths showed almost no decrease over many sessions; they were replaced by other rats.

Experimental room and beacons. The experiment was conducted in a room adjacent to the room used in the previous experiment. The overall dimensions of the rooms were identical, but no closet protruded into the NW corner. The striped cylinder was used as a beacon, and the second beacon was a gray plastic inverted cone. The cone stood $12 \mathrm{~cm}$ high and was $2 \mathrm{~cm}$ wide at its base and $8.5 \mathrm{~cm}$ wide at the top. The base of the cone sat on top of a black weighted disk $16 \mathrm{~cm}$ in diameter. The cone had an open compartment $4.5 \mathrm{~cm}$ deep at the top where 70 Brazil nut pieces could be placed. Each beacon could be located at one of two positions, which were separated by $180 \mathrm{~cm}$. Position A was $216 \mathrm{~cm}$ and $15^{\circ} \mathrm{NE}$ of the center of the home zone, whereas Position B was $235 \mathrm{~cm}$ and $30^{\circ} \mathrm{NW}$ from the same reference point. White plastic lids, $10.5 \mathrm{~cm}$ in diameter with a $1.5-\mathrm{cm}$ lip around the edge, were placed over the beacons during training and testing.

Pretraining. The first two sessions proceeded as described previously. The lids were placed over the habituation beacon starting on the 3rd day of pretraining, partially covering its top. Across the remaining trials of pretraining, each rat was trained to remove the lid with its nose or teeth to get to the food below.

Phase 1: acquisition. The rats were allowed to make five trips per session, during which they could enter the room, remove the lid from the $\mathrm{S}+$ beacon, extract a nut, and return to the home base. The cylinder and the cone were both present during all trips, one at Position A and one at Position B. For Group Stable, the food was always located in the same beacon, and that beacon was in the same place for every trip and every session. In contrast, the cone and the cylinder alternated according to a block-randomized schedule between Positions A and B during the course of a session for the rats in Group Varied, but the food was always in the same position. The assignment of the cone, cylinder, and rewarded location combinations was randomly selected and balanced as much as possible for the rats in both groups.

A session began when the rat was released into the room to make its first trip to the cylinder. The guillotine door was closed after the animal returned home, and a 1.5-min ITI ensued, during which time the experimenter entered the room and, depending on whether the rat was assigned to Group Stable or Group Varied, either touched the cylinder or moved it to a new position in the room, respectively. The same procedures were used for the first four trips during a session. Following the fourth complete trip, a 3-min ITI commenced, during which time the floor of the room was cleaned and the beacon was moved, if necessary. The rat was then allowed to make a fifth trip to the cylinder. One session was conducted per day for 4 days.

Phase 2: place testing. On Days 5 and 6, the first four trips in a session were identical to those described in Phase 1 for both groups. Between the fourth and the fifth trips, a 3-min ITI, the procedures of which were similar to those described during acquisition, oc- curred. A place test like that described in Experiment 1A was given on the fifth trip (without beacons and nonreinforced).

Phase 3: reversal. On Days 7-10, all five daily trips proceeded as described during Phase 1, except that the place at which the nuts were found was the location opposite that during the previous two phases of the experiment (e.g., Location A in Phase 1, Location B in Phase 3). For the rats in Group Stable, the S+ with the nuts inside was the same as in Phases 1 and 2. The rats in Group Varied continued to experience a rotation of the beacons from location to location across trials.

Phase 4: reversal with place tests. This phase was identical to Phase 2, except that food was in the same place as in Phase 3 for all rewarded trips.

\section{Results}

Acquisition, reversal, and behavior in the place tests were not affected significantly by whether the identity of the positive beacon remained the same from trip to trip or varied (Figure 4). For Days 1-4, the main effects of days and of trips were highly significant $[F(3,54)=$ 12.73 and $F(4,72)=21.67$, respectively]. No other main effects or interactions were even close to significance (all $F \mathrm{~s}<1.3$ ). On the four daily rewarded trips on Days 5 and 6 , the only significant effect was that of trips $[F(3,54)=6.50]$. Trip 1 differed from the subsequent trips (Fisher's LSD tests) for all other main effects and interactions in the groups $\times$ days $\times$ trips ANOVA on these 2 days $(F \leq 1.54)$. The groups $\times$ days ANOVA on the results of the place tests on these 2 days revealed no significant effects [for groups, $F(1,18)=3.19, p=.091$; for days, $F(1,18)=1.60$; for their interaction, $F(1,18)=$ 1.02]. The rats in Group Stable entered the goal zone within $20 \mathrm{sec}$ on 36 of 40 occasions during the four daily rewarded trips across Days 5 and 6. Likewise, the rats in Group Varied entered the goal zone during 40 of 40 trials during this period.

The patterns of statistical significance were similar in Phases 3 and 4. For the five daily rewarded trips on Days $7-10$, the main effects of days and of trips and the trips $X$ days interaction were all significant $[F(3,54)=35.46$, $F(4,72)=12.95$, and $F(12,216)=2.54$, respectively $]$. The groups $\times$ trips interaction was not significant $[F(4,72)=1.27]$, nor were any other effects significant $(F \mathrm{~S}<1.0)$. On the four daily rewarded trips on Days 11 and 12, there were significant groups $\times$ days and groups $X$ days $\times$ trips interactions $[F(1,18)=5.54$ and $F(3,54)=$ 2.93 , respectively]. Group Varied showed a difference between Days 11 and 12 that was not shown by Group Stable (see Figure 4; all other $F_{\mathrm{s}} \leq 1.75, p \mathrm{~s}>.167$ ). The rats in Group Stable entered the goal zone on 40 of 40 rewarded trips during the first four trips on Days 11 and 12. The rats in Group Varied entered the goal zone on 39 of 40 trips during this same period.

As in the first pair of place tests, the groups $X$ days ANOVA on the transformed path lengths in the place tests revealed no significant effects involving groups $(F \mathrm{~s}<1.0)$. However, there was a significant main effect of days in this analysis $[F(1,18)=5.99]$. As can be seen in Figure 4, in the final place test, the rats did not go as 


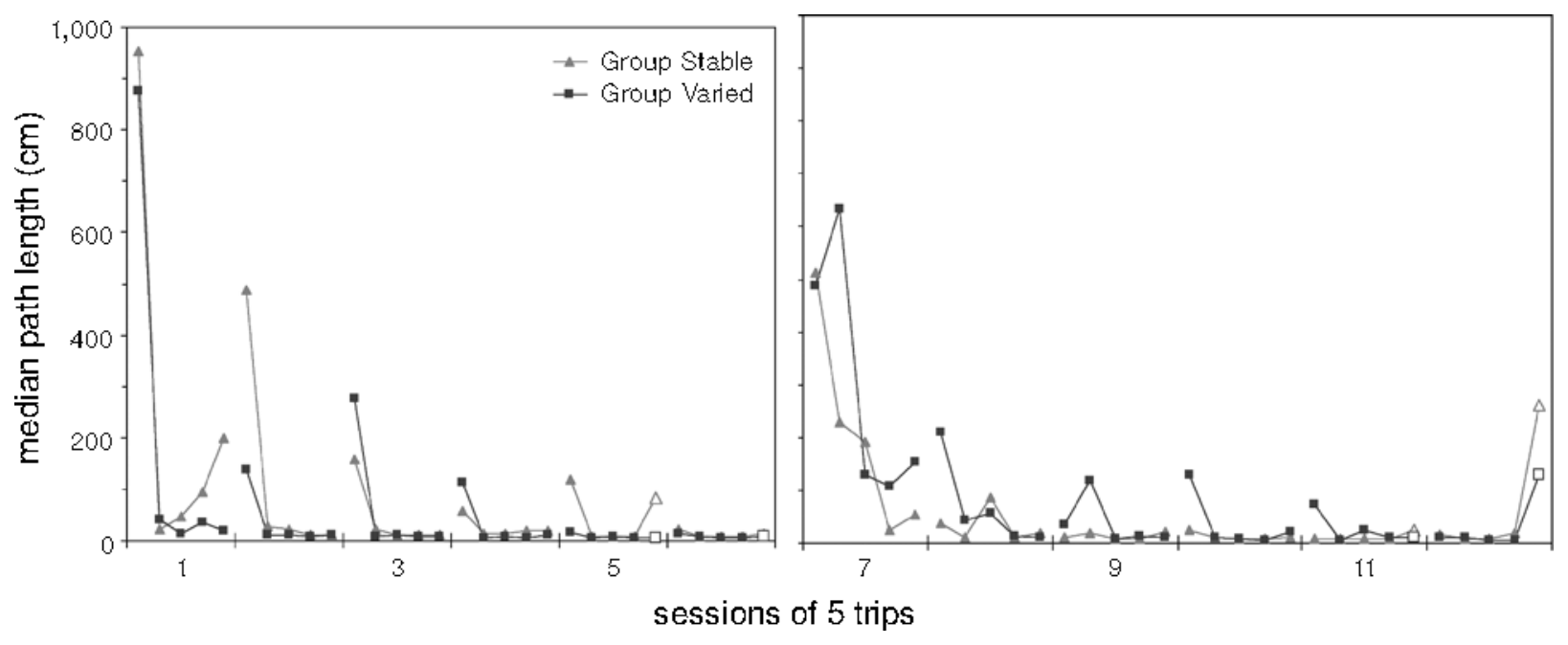

Figure 4. Median path lengths to the S+ place for the two groups of rats in Experiment 2. Left panel, original discrimination; right panel, reversal, with reinforced place on the opposite side of the room. Open symbols indicate place tests, when the beacon was removed.

directly to the usual location of the $\mathrm{S}+$ beacon as in the three earlier place tests. As in Experiment 1B, this could be an effect of repeated place tests. The goal zone was entered during the place tests on 17 of 20 occasions by the rats in Group Stable and on 18 of 20 occasions by the rats in Group Varied.

\section{Discussion}

Unlike some investigators who have found evidence for cue competition in other spatial learning paradigms (Diez-Chamizo et al., 1985; March et al., 1992; Redhead et al., 1997), we failed to find any evidence that the beacon in our paradigm interfered with learning other cues that identified the location of a goal. However, there are other cases of apparent failure of beacons to interfere with place learning. In mice, the presence of a beacon facilitates learning the location of the dry platform in a water maze (Chapillon \& Roullet, 1996). Lavanex and Schenk (1995) reported comparable results for rats finding food. Place cues may have out-competed beacon cues in the present situation. The findings from Experiments $1 \mathrm{~A}$ and $1 \mathrm{~B}$ indicate that place learning is very strong, as compared with beacon learning in our testing situation. For example, in Experiment 1B during the beginning of testing, the rats tended to return to the location that the goal had occupied during Experiment 1A. Likewise, when the position of the rewarded location changed during Phase 2 of Experiment 2, the rats in Group Stable tended to return to the location where food had been during Phase 1, even though the $\mathrm{S}+$ beacon was at the new location.

There are a number of potential reasons for the apparent failure of relative validity of place cues to affect later place learning in the present experiment. Consistent with the idea that spatial learning obeys an overall error-correction rule, as in associative learning, it might be observed that the beacon appears to be a relatively weak cue, as compared with the ensemble of other cues identifying the place where food is found. In conditioning, a CS of low salience may fail to overshadow a more salient CS (Mackintosh, 1976). Despite the fact that the patterns and shapes of the beacons appeared very salient to us, the data from Experiments 1 and 2 indicate that this may not have been true from the rats' point of view. However, data from Experiment 4 (see below) showed that the rats were able to distinguish the beacons. In the present experiment, to find the food efficiently, it was sufficient to learn the place where it was located. Because place learning seems to be very quick in this situation, it may have out-competed the beacon as a spatial cue, even when the beacon was relatively more valid. If, in contrast, beacon cues and other spatial cues were learned in parallel and compete for control of performance, the groups should have differed at the beginning of the reversal phase, and they did not.

Another possible explanation of the present results is that the rats in both groups learned the task in terms of the fixed geometric relationship between the beacons. On this view, the results reflect the same mechanism as that reflected in the data reported by Benhamou and Poucet (1998) for the rats in the water maze (see also Cheng, 1986). In their experiments, the location of the dry platform was defined by a triangular array of landmarks. Although the rats could discriminate these landmarks, orientation was unaffected when the landmarks were swapped with one another in the array. Biegler and Morris (1999) reported a similar effect in a food-finding task. That is, although the rats had to attend to the landmarks to solve these tasks, they did not encode the features specific to each one. Similarly, the rats in this experiment may have encoded the task as an approach to the left or the right of the array of two beacons. To account for their 
short paths in the place tests, however, it is necessary to assume that they also learned the location of the rewarded beacon or the linear array of beacons in terms of landmarks in the room, the room's overall spatial geometry, and/or the outward path from the home base.

\section{EXPERIMENT 3}

The results from Experiment 2 failed to reveal any impact of differing relative validities of places and beacons in our task. However, beacon cues should eventually be learned if they are the best predictors of food. Once beacon cues have been learned, one can ask whether they will compete with place cues. Experiment 3 was a test of whether well-learned beacon cues interfere with learning place cues that are subsequently added (see Table 2 ). In Phase 1, the rats in Group Day found the beacon and the food in a different place for each session. For the rats in Group Trip, the beacon and the food moved for every trip, making the beacon the only cue to the location of food. How the past predictive value of the beacon influenced learning about a new place was tested in Phase 2, during which the beacon and the food were in the same place for three sessions. The beacon and the food were absent on the last trip of each session in order to test what the rats had learned about that place. In the final session of this phase, the beacon was moved to a new place in order to put place and beacon learning in conflict.

This design is similar to that in Roberts and Pearce's (1999) Experiment 3. They found blocking of place (primarily landmark) learning in the water maze by a welllearned beacon in a group analogous to the present Group Trip (their Group Trial Same), but not in a group analogous to Group Day (their Group Session Same). However, as was mentioned earlier, food-carrying rats that have learned to use a reliable beacon for homing still encode the present location of the home with respect to landmarks in the testing room (Maaswinkel \& Whishaw, 1999; Whishaw \& Tomie, 1997). The similarity of our testing situation to that used by Whishaw and colleagues suggests that a beacon at the goal might not reduce the learning of place cues indicating the location of reward.

\section{Method}

Animals and test environment. Sixteen adult male Long-Evans rats, 15-20 weeks of age and weighing 291-336 g at the start of testing, were used. All of the rats had experience in an unrelated project, as described in Experiment 2. They were maintained as described previously. Testing was conducted in the same room as that described in Experiment 1A.

Pretraining. All the rats were handled and pretrained as described in Experiment 1A, except that five trips, instead of six, were allowed during each session.

Acquisition. The rats were randomly assigned to either Group Trip $(n=8)$ or Group Day $(n=8)$ following pretraining. The stocked cylinder was moved to a new position before the start of each trip for the rats in Group Trip. For the rats in Group Day, it was placed at a new location at the start of each day, but it remained at the same position for all trips in a day. Sixteen of the 48 beacon locations were used. Four well-dispersed locations were selected from each quadrant. For Group Trip, each quadrant was used at least once during each session, in random order, and exposure to the quadrants was balanced across blocks of 4 days. The beacon position in each quadrant was randomly selected for each trip, and all 16 beacon locations were used at least once for this group across a block of 4 days. For the rats in Group Day, the cylinder was placed in a randomly selected quadrant each day, and exposure to each quadrant was balanced across blocks of 4 days. The location within each quadrant was also randomly selected each day, and all 16 locations were used once during acquisition. Each rat in both groups encountered a unique sequence of beacon-location/ quadrant combinations. Sessions proceeded as described for Experiment 2. One session was conducted per day, and acquisition continued for 16 days.

Place tests. On Days 17-19, the first four trips of the five-trip session proceeded identically to those during acquisition, except that, for both groups, the cylinder was now at a fixed position of $216 \mathrm{~cm}$ and $15^{\circ} \mathrm{NE}$ of the center of the home zone. Between the fourth and the fifth trips, there was a 3-min ITI, following procedures like those during acquisition. A place test like that described in Experiment 1A followed the ITI (without beacon and nonreinforced).

Reversal. On Day 20, all five trips proceeded as described for acquisition, except that the cylinder was $200 \mathrm{~cm}$ and $28^{\circ} \mathrm{NW}$ of the center of the home zone for all five trips for both groups.

\section{Results}

By the end of Phase 1, all the animals were going directly to the beacon on the first daily trips (Figure 5). However, the course of acquisition was very different in the two groups. At first, the rats in Group Day took long and indirect paths each time the beacon was in a new place. However, from the 1 st day of training onward, all the subsequent trips were much shorter. With experience, the influence of the previous day's place became less apparent, and the trips were almost equally short from the beginning of sessions. The rats in Group Trip, in contrast, had relatively long paths throughout the first few sessions, but they began to track the beacon well on

Table 2

Design of Experiment 3

Phase of the Experiment

\begin{tabular}{lllc} 
& \multicolumn{1}{c}{ Acquisition* } & \multicolumn{1}{c}{ Place Testing $\dagger$} & Reversal \\
\cline { 2 - 4 } Group & $\mathrm{B}^{+}$in new place each session & $\mathrm{BP} 1^{+}$on Trips 1-4; P1 alone on Trip 5 & $\mathrm{BP}^{+}$ \\
Group & $\mathrm{B}^{+}$in new place each trip & $\mathrm{BP} 1^{+}$on Trips 1-4; P1 alone on Trip 5 & BP2 $^{+}$ \\
\hline
\end{tabular}

${ }_{*} \mathrm{~B}$, the beacon. The striped cylinder served as B for all the rats. Superscript + , reward was in the beacon. The acquisition phase continued for 16 sessions of five trips. †P1 and P2, two places. Three sessions of five trips each. $\quad$ P2 2 was on the opposite side of the room from P1 and about the same distance from the home box. One session. 


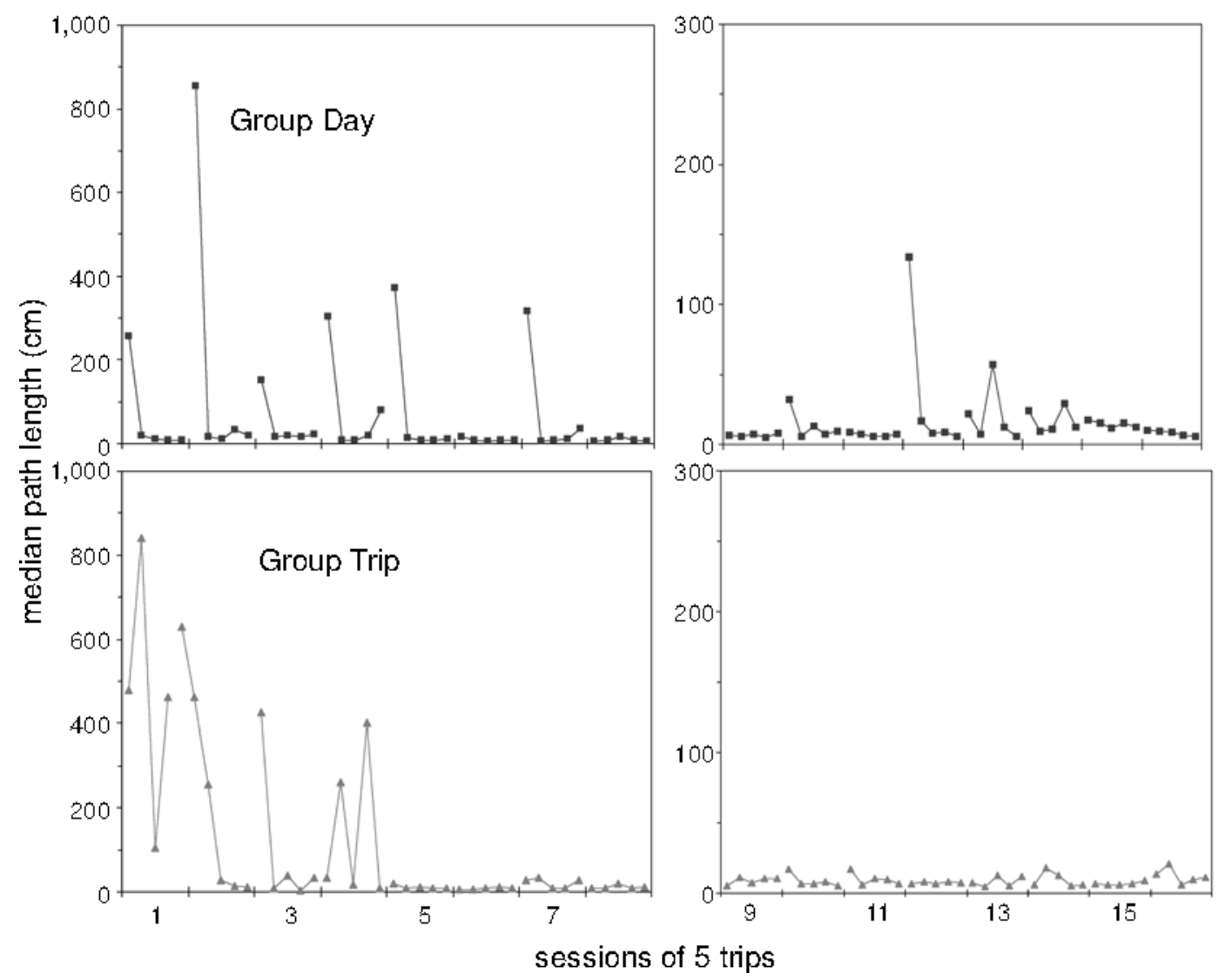

Figure 5. Median path lengths throughout acquisition for the two groups of rats in Experiment 3. The beacon was in a new location on every trip for Group Trip and on every session for Group Day. Note the change of scale between the first eight and the last eight sessions.

every trip sooner than did the rats in Group Day. The differences between the paths of the two groups early in acquisition reveals that learning based on spatial cues other than the beacon exerted a powerful effect on the rats' behavior. In the first few sessions, even a single trip with the beacon in a new place was enough to bias the rats to return there on the next trip, rather than follow the beacon to a new place. Similar one-trial place learning was seen in the water maze (Pearce et al., 1998; Steele \& Morris, 1999).

A groups $\times$ days $\times$ trips ANOVA on the transformed path lengths for the 16 days of acquisition revealed a significant effect of days and a significant groups $\times$ days interaction $\left[F_{\mathrm{S}}(15,210)=9.25\right.$ and 2.04 , respectively $]$. Groups also interacted significantly with trips, and the effect of trips was also significant $\left[F_{\mathrm{s}}(4,56)=9.88\right.$ and 19.64 , respectively]. No other main effects or interactions reached significance (all $F \mathrm{~S}<1.0$ ).

In the first 3 days of Phase 2, all the rats continued to approach the beacon very directly in the four daily reinforced trips (Figure 6). An ANOVA on the transformed path lengths confirmed that Groups Trip and Day did not differ during these trips. Only the main effect of days was significant $[F(2,28)=6.78$; for groups $\times$ days,
$F(2,28)=1.18$; for groups $\times$ trips, $F(3,42)=2.35$; all other $\left.F_{\mathrm{s}}<1.0\right]$. This finding suggests that although the rats had learned to track the beacon, they were learning about its place in the room when it did not move for 3 successive days. Notwithstanding their similar behavior when the beacon was present, the two groups behaved differently in the place tests. The rats in Group Day took significantly shorter paths to the place where the beacon had been than did the rats in Group Trip, indicating that they had learned more about the place where food was now located. A groups $\times$ days ANOVA on the transformed path lengths from the place tests confirmed a significant groups effect $[F(1,14)=8.74]$. Neither the effect of days nor its interaction with groups approached significance $\left(F_{\mathrm{S}}<1.0\right)$. A similar difference in performance between the groups is revealed by the goal zone entry data. The rats in Group Day entered the goal zone within $20 \mathrm{sec}$ during 17 of 24 place tests, and the rats in Group Trip entered the goal during 14 of 24 place tests.

Moving the beacon to a new place for the reversal session put the rats' tendency to approach the beacon in conflict with any tendency to approach the place where the beacon had been for the three previous sessions. Because the rats in Group Trip had evidently learned less 


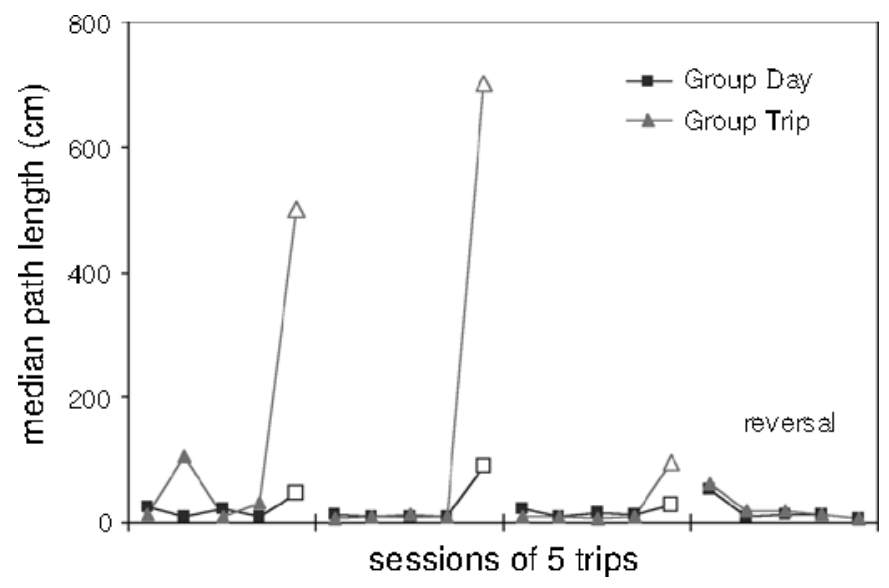

Figure 6. Median path lengths during Phase 2 of Experiment 3. Open symbols indicate place tests, when the beacon was removed. The beacon was moved to a new location for the final, reversal session.

about that place and, possibly, more about the beacon, they might have been expected to have shorter paths than did the rats in Group Day in this test. However, the groups did not differ in this stage. A groups $\times$ trips ANOVA on the transformed path lengths for this session revealed only a significant effect of trips $[F(4,56)=6.41$; for groups, $F(1,4)<1$; for groups $\times$ trips, $F(4,56)=1.08$ ]. The first trip was significantly longer than all the subsequent trips; of these, only Trips 3 and 5 differed from each other (Fisher's LSD tests).

\section{Discussion}

For the subjects in Group Trip, the beacon moved from trial to trial, so that the last location of food (i.e., place cues) never predicted its present location. The presence of this well-learned beacon appeared to compete with place learning during Phase 2 when both place and beacon cues were available. Specifically, when the beacon was removed during place testing and place cues were still present to guide the animal, the path lengths generally increased, as compared with (1) trials in which both beacon and place cues were available and (2) trips for Group Day for which place cues had been more relevant during training. Notably, path lengths shortened for Group Trip by the third series of place tests, indicating that the rats had learned about both place and beacon cues. These results are consistent with some other studies that have revealed effects of cue competition in the water maze and radial maze (e.g., Diez-Chamizo et al., 1985; Roberts \& Pearce, 1999).

\section{EXPERIMENT 4}

In Experiment 3, the place cues used during Phase 2 were not novel; rather, they were present but irrelevant during Phase 1. The difference between Group Trip and Group Day could, therefore, reflect a difference in the degree to which place cues were irrelevant in Phase 1, rather than a difference in the degree to which the beacon was associated with food. Competition for attention and competition for associative strength are not mutually exclusive, but they can be distinguished experimentally as well as theoretically. This was done, for example, by Roberts and Pearce (1999) in their demonstration of spatial blocking in the water maze. Their Experiment 3 included two groups of rats for which a beacon was relevant and place cues present but irrelevant in Phase 1 because the beacon and the dry platform moved on every trial. In Phase 2, both of these groups were trained with a single beacon and the same place cues, but now place cues were relevant because the beacon and the dry platform were no longer moved. For one group, the beacon was novel, and these animals learned more about the location of the platform than did the animals that had their previously trained beacon present for Phase 2 , indicating that place learning was blocked by the informative beacon in the latter group. Learned irrelevance was further controlled for in a subsequent experiment (Roberts \& Pearce, 1999, Experiment 4), the results of which again indicated that the beacon and the landmarks were competing for predictive value.

To discover whether learned irrelevance could account for the group differences observed during testing in Experiment 3, in Experiment 4 we compared two groups of rats for which place cues were equally irrelevant in Phase 1 (Table 3). These rats learned to discriminate between two differently shaped and patterned beacons, both of which were in different places on every trip. In Phase 2, all the rats found a single beacon with food in the same place in the room for 3 successive days and had a test of place learning at the end of each day. The results from Experiment 2 indicate that when two beacons remain in the same place across trials, learning about the geometric relationship between them may dominate any 
Table 3

Design of Experiment 4

\begin{tabular}{|c|c|c|c|}
\hline \multirow[b]{2}{*}{ Group } & \multicolumn{3}{|c|}{ Phase of the Experiment } \\
\hline & Acquisition* & Place Testing $\dagger$ & Reversalł \\
\hline Stable & $\mathrm{B} 1^{+} / \mathrm{B} 2^{0}$ in new places before each trip & $\mathrm{B} 1 \mathrm{P} 1^{+}$on Trips $1-4 ; \mathrm{P} 1$ alone on Trip 5 & $\mathrm{~B} 1 \mathrm{P} 2^{+}$ \\
\hline Different & $\mathrm{B} 1^{+} / \mathrm{B} 2^{0}$ in new places before each trip & $\mathrm{B} 2 \mathrm{P} 1+$ on Trips $1-4 ; \mathrm{P} 1$ alone on Trip 5 & $\mathrm{~B} 2 \mathrm{P} 2^{+}$ \\
\hline Control & NA & $\mathrm{B} 1 \mathrm{P} 1^{+}$on Trips $1-4 ; \mathrm{P} 1$ alone on Trip 5 & 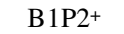 \\
\hline
\end{tabular}

*B1 and B2, the two beacons. P1 and P2, the two rewarded places. The striped cylinder and the gray cone served as either B1or B2 in a counterbalanced manner. Superscript + and 0 signify reward and nonreward, respectively, in the beacon. Acquisition lasted for 16 sessions of five trips each. †Three sessions of 5 trips each. $\quad$ †P2 was on the opposite side of the room from P1 and about the same distance from the home. One session.

learning about the features that differentiate them. Hence, we used one beacon during Phase 2 of the present experiment. This also allowed us to more directly compare performance during the final phases of Experiments 3 and 4. As in Experiment 3, the beacon with food moved to a new place in the final, 4th day of Phase 2. For Group Same, the beacon in Phase 2 was their former positive (food-containing) beacon. For Group Different, the formerly empty beacon now contained food. If beacon learning competes with place learning, the rats in Group Same, for which the beacon already predicts food, should learn less about the fixed place where it is now located than the rats in Group Different, which expect no food in that beacon. However, if the relatively poor place learning by Group Trip in Experiment 3 reflects only learning to ignore place cues, Group Same and Group Different should learn equally little about the fixed location of the beacon in Phase 2. Phase 2 also included a group of naive control rats in order to reveal the extent to which both Group Same and Group Different had learned to ignore place cues during Phase 1.

\section{Method}

Animals. Thirty male Long-Evans rats 12-24 weeks of age and weighing $277-432 \mathrm{~g}$ at the start of testing were used. They were maintained at $85 \%$ of their ad-lib body weights, as described previously. Eleven were experimentally naive, and the others had had experience similar to that of the rats in Experiment 2. All the rats were handled, and then 10 rats were assigned to each of Group Same, Group Different, or a control group, matched as closely as possible for previous experience.

Experimental room and beacons. The experiment was conducted in the room described in Experiment 2. The cone and the cylinder were used as beacons. Three well-dispersed locations from each quadrant were used for the beacon during acquisition and testing.

Pretraining. Group Same and Group Different encountered pretraining immediately after being handled, whereas the control group experienced pretraining while the other two groups were finishing the last 4 days of Phase 1. Pretraining proceeded as in Experiment 2.

Phase 1: acquisition. Only Groups Same and Different experienced this phase. The cylinder and the cone were both in the room during each trip. For half the rats in each group, the cylinder was the rewarded beacon $(\mathrm{S}+)$ on every session and the cone was the unrewarded $(\mathrm{S}-)$ beacon. The other rats had the reverse assignment. Before the start of each trip, the S+ was stocked with food, and the $\mathrm{S}+$ and $\mathrm{S}-$ were moved to new locations (see below). The rats were allowed to make five trips per session, during each of which they could enter the room, extract a nut from the $\mathrm{S}+$, and return to the home box. After each of the first three trips, the rat was secured in the home box, and a 1.5-min ITI ensued, during which the experimenter moved the beacons to their locations for the next trip. As in Experiment 3, there was a 3-min ITI between the fourth and the fifth trips, and the room was cleaned. One acquisition session was conducted per day for 16 days.

The selection of beacon locations on each trial was constrained in that the two beacons must be (1) separated by at least $45^{\circ}$ (as viewed from the rat's entry) and by $60 \mathrm{~cm}$ and (2) in different quadrants. With this rule, the beacons could be in 80 unique $\mathrm{S}+/ \mathrm{S}-$ location combinations, each used once during the course of acquisition. The $\mathrm{S}+$ and $\mathrm{S}-$ were located in each quadrant at least once per session, and the assignment of the $\mathrm{S}+/ \mathrm{S}-$ location combinations followed a block-randomized schedule that was different for each rat.

On Day 14, the first four trips proceeded as described above, but during the ITI between Trips 4 and 5, the food was removed from the $\mathrm{S}+$ beacon. The beacons were not cleaned, but any potential residual odor cues were present for each beacon (the cylinder and the cone were balanced as rewarded beacons across subjects). The beacons were placed at the same distance and angle from the center of the home zone, one to the NE and one to the NW. During Trip 5, or time test, the amount of time the rat spent in the $30-\mathrm{cm}$ zone surrounding each beacon was recorded, as well as its path length to its $\mathrm{S}+$. After $20 \mathrm{sec}$, the experimenter entered the room, and the rat returned to the home box.

Phase 2: place testing. The rats in all three groups experienced three sessions with place tests (Days 17-19). The first four trips of the five-trip session proceeded identically to those in Phase 1, except that only one of the two beacons was placed in the room and at a fixed position of $216 \mathrm{~cm}$ and $15^{\circ} \mathrm{NE}$ of the center of the home zone for the first four trips in a session. The rats in Group Same encountered the S+ they had experienced during acquisition. For the rats in Group Different, the beacon assigned as the $\mathrm{S}-$ during acquisition was now stocked with nuts and served as the $\mathrm{S}+$ for the remainder of the experiment. Half the rats in the control group were trained with the cylinder in this phase, and half with the cone. Between Trips 4 and 5, a 3-min ITI occurred, as described for acquisition. A place test like those in the previous experiments was given on Trip 5 (without beacon and nonreinforced).

Reversal. On Day 20, all five trips proceeded as described during the first four trips on Days 17-19. The beacon, with food, was moved to the same position as that which it had occupied during reversal in Experiment 3.

\section{Results}

As in the previous experiments, path lengths to the beacon containing food became shorter with training (Figure 7). However, path lengths varied much more from trip to trip than in Experiment 3 (Figure 5). Because the S+ and $\mathrm{S}-$ were positioned quasi-randomly in the room (see 


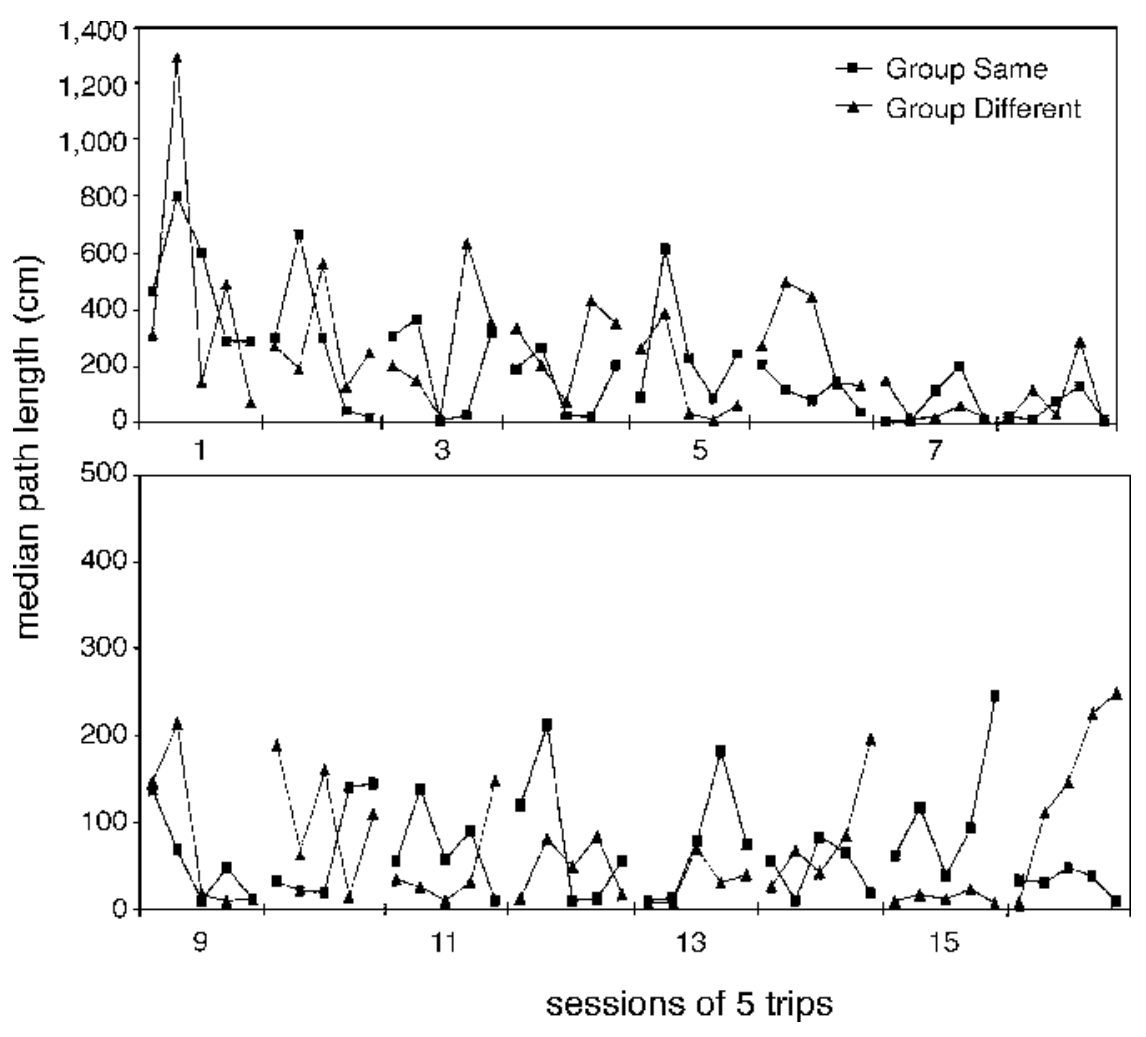

Figure 7. Median path lengths to the $\mathrm{S}+$ beacon during acquisition of a discrimination between two beacons in Phase 1 of Experiment 4. Note the change of scale between the first eight and the last eight sessions.

the Method section), about half the time the $S$ - was closer to the rat's entry than was the S+. The rats often headed first toward the $S-$, even though late in training they did not actually push off the lid or even go all the way to the beacon. However, the results of the unreinforced time test on Day 14 clearly show that although paths to the $\mathrm{S}+$ were still comparatively long, the rats discriminated it from the $\mathrm{S}-$. They spent a mean of $11.7 \mathrm{sec}(S D=4.62 \mathrm{sec})$ of this 20 -sec test in the $30-\mathrm{cm}$ zones around the beacons. A mean of $92.8 \%( \pm 0.22 \%)$ of this time was in the S+ zone. All but 1 of the 20 rats spent more time near $S+$ than near $\mathrm{S}-$. These results also show that the odor of the nuts emanating from the beacons is unlikely to be what controlled the rats' behavior in this situation.

The rats destined for Group Same did not differ from those destined for Group Different during acquisition. In the groups $\times$ days $\times$ trips ANOVA on the transformed path lengths over the whole 16 days, the effect of days was significant $[F(15,270)=8.94]$. The main effects of groups and of trips were not significant [for groups, $F<1$; for trips, $F(4,72)=1.58$ ] . The groups $\times$ trips interaction also was not significant $(F<1)$. However, the groups $\times$ days interaction was significant $[F(15,270)=2.01]$, as were the trips $\times$ days and the groups $\times$ trips $\times$ days interactions $\left[F_{\mathrm{s}}(60,1078)=2.53\right.$ and 1.60 , respectively $]$. The effects with groups appear to have been driven by relatively large differences between the groups across a limited number of days. For example, during Day 6, the rats in Group Different had larger path lengths across most trips than did the rats in Group Same. However, on Day 8, the path lengths for the groups did not differ. Combined, the effects increased the ability to detect an interaction containing the group factor. In general, as can be seen in Figure 7, none of these interactions reflected a systematic difference between the two groups, since the group that had the largest median path length generally changed across days (e.g., Days 9-12). Indeed, if the analysis had used a blocking factor that collapsed performance across several days, the interactions with the group factor would likely not be apparent.

In the four rewarded daily trips of Phase 2, the paths of the rats in all three groups became shorter over the 3 days of training with a single beacon in a fixed place (Figure 8). Past experience with that beacon also had an effect. In the groups $\times$ trips $\times$ days ANOVA on transformed path lengths, the effect of groups was not significant $[F(2,27)=$ 1.10], but there were significant effects of days and trips and a significant groups $\times$ trips interaction $[F(2,54)=$ $18.42, F(3,81)=3.03$, and $F(6,81)=3.75$, respectively $]$. Across the 3 days, Fisher's LSD comparisons indicated that the rats in Group Same had significantly shorter first trips than did the rats in Group Different or the naive con- 


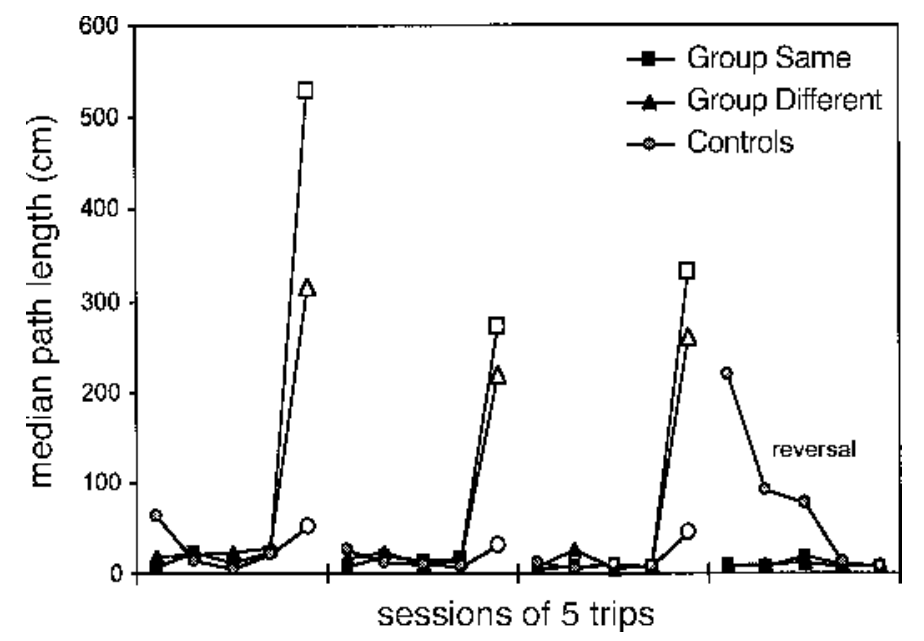

Figure 8. Median path lengths during Phase 2 of Experiment 4. Open symbols indicate place tests, when the beacon was removed. The beacon was moved to a new location for the final, reversal session.

trols (the median values displayed in Figure 8 do not reveal this trend in the data, however). None of the remaining interactions was significant (all $F_{\mathrm{S}}<1.2$ ).

The place tests showed that the naive controls had learned much more about the place in the room where food was found than had the rats in either Group Same or Group Different. For the rats in the latter two groups, having learned to track a beacon regardless of its location apparently resulted in a tendency to ignore place cues, as compared with the controls. For the place tests on the first 3 days of Phase 2, a groups $\times$ days ANOVA revealed a significant effect of group $[F(2,17)=15.83]$, no effect of days, and no interaction $\left(F_{\mathrm{S}}<1.0\right)$. The controls differed from Groups Same and Different, which did not differ significantly from each other (Fisher's LSD tests). This same pattern of group differences was maintained in the final, reversal day of Phase 2, with the beacon in a new place. The rats in Groups Same and Different had very short paths throughout this session, whereas the control rats had relatively long paths at first. For the reversal session, an ANOVA on the transformed path lengths revealed significant effects of groups and trips and a significant groups $\times$ trips interaction $[F(2,27)=$ $12.17, F(4,108)=4.72$, and $F(8,108)=2.52$, respectively]. The controls differed significantly from the other two groups on the first two trips of the session (Fisher's LSD tests). The rats in all the groups showed a similar ability to reach the goal during testing. The rats in Group Same reached the goal on 21 of 30 trips across the three place tests. Similarly, the rats in Group Different reached the goal on 22 of 30 trips, and the rats in the control group reached the goal on 26 of 30 occasions.

\section{Discussion}

The results of Phase 1 indicate that in the present situation, tracking a beacon that moves from place to place is a difficult task. To learn it, rats must in some way in- hibit a strong tendency to return to the last rewarded place. As was mentioned in the Discussion section of Experiment 3 , this could be accomplished by learning less about place cues (differences in associative strength) or by altering the relative weights given to place cues and the beacon in determining performance. The latter explanation implies that rats that have learned to track a beacon continue to learn about its location but approach the beacon, rather than the remembered place. However, the findings from Phase 2 of Experiment 4 suggest that the rats tended to ignore cues other than the beacon that indicated the location of the goal. Those tests show that the rats that learned to follow a beacon in Phase 1 learned less about a fixed place in Phase 2 than did naive rats.

If the predictive values of the positive and negative beacons transferred to Phase 2 from the discrimination task in Phase 1, Group Same should show the least evidence of place learning in Phase 2, Group Different should show the most, and the controls should be intermediate. However, not only were the controls not intermediate, Groups Same and Different did not differ significantly in the place tests or in the reversal session. Nevertheless, Group Same had significantly shorter paths than did Group Different or the controls on their first daily trips in this phase, which indicates that the specific values of the beacons learned in Phase 1 did transfer to Phase 2 to some extent. The rats in Group Same also tended to have slightly longer paths than did the rats in the other two groups in the place tests (Figure 8), consistent with their having learned less about place cues, but this difference was not significant. Thus, the competition among spatial cues demonstrated in both this experiment and Experiment 3 must be attributed primarily to learned irrelevance of place cues, rather than to competition between well-attended place and beacon cues. The present results therefore would seem to differ from those of Roberts and Pearce (1999) and of DiezChamizo et al. (1985), who ruled out learned irrelevance 
for place cues in their demonstrations that beacon cues can block place learning.

\section{GENERAL DISCUSSION}

In the present experiments, tests of cue competition were used to address the question of how beacon cues interact with other spatial cues during learning about the location of a goal. Although this issue has been addressed previously, only a limited number of testing paradigms have been used. The studies of rats, mice, and hamsters searching for items to carry home that were reviewed in the introduction to this article suggest that beacons do not always compete with other spatial cues for the control of search behavior. In the present set of experiments, we tested how rats acquire information about beacons and places, using a task that is consistent with their natural foraging behavior. The results show that rats can learn to track a food-containing beacon that is always found in different places and to discriminate it from a similar but empty beacon but that cues from beacons do not appear to compete directly with place cues for either learning or performance. Rather, as they learn to track the beacon, rats learn to pay less attention to place cues. And when a beacon is redundant with place cues, as in Experiment 2, cues to its identity seem to be attended to very weakly, if at all.

The present findings differ from those of some previous studies involving competition between cues at a goal and more remote spatial cues in which a radial maze or a water maze was used (e.g., Diez-Chamizo et al., 1985; Redhead et al., 1997; Roberts \& Pearce, 1999). Differences in the experimental parameters used in the present experiments and those used in these other studies may have contributed to these different results. One such factor might be the duration of training prior to testing for competition. Using simple light and tone CSs, Bellingham and Gillette (1981) found that overshadowing was robust after relatively few training trials but was attenuated after a relatively large number of such trials. In the present situation, competition between the beacon and the place cues may have been observed if testing had occurred after relatively fewer training trials. Although the cues used in that study and those used in the present set of experiments were quite different, other studies in which spatial competition in the water maze was examined have shown evidence for cue competition following relatively fewer trials (Diez-Chamizo et al., 1985; Redhead et al., 1997; Roberts \& Pearce, 1999). The act of swimming in the water maze could potentially distract rats from spatial information and increase reliance on one set of cues at the expense of others (i.e., cue competition). In contrast, the act of foraging in the room might have favored processing a richer variety of cues. In addition, the cost associated with search in the present situation may be less than that with other procedures. When the beacon was removed during the place tests in the present study and the conditions were somewhat am- biguous, the rats might have started looking for the beacon even if they had partially encoded place. In contrast, in the water maze, the aversive conditions of the test may not favor such exploration, and in a radial maze, exploration entails traveling to new arms, again a relatively costly strategy.

Differences in the spatial cues available to the animals tested using the present paradigm and the radial and water maze might have also contributed to differences in cue competition reported using these procedures. In particular, in the present experiments, in addition to using distal landmarks and beacons, the rats might have learned a fixed path to the goal or used dead reckoning from the starting point when the goal remained in the same location across sessions (e.g., Experiment 1A) or within a daily session (e.g., Group Day in Experiment 3). Although dead reckoning is usually thought of as creating a temporary record or working memory of current position relative to a starting place (cf. Gallistel, 1990; Shettleworth, 1998), Etienne et al. (1998) have found that hamsters also store a longer term memory of the dead reckoned location of a food source, relative to the nest, and use it to compute new routes to the food. This implicit computation relies on self-generated cues and is independent of landmarks; because it generates new paths, it is not the same as route learning. Both route learning and dead reckoning are typically discouraged in the water maze by starting the animal from different locations across trials. This difference may not always hold true, however, since in the water maze, if the animal is not disoriented, it may be performing dead reckoning with respect to the point of departure, or even with respect to fixed locations in the wider environment, such as the home cage (cf. Dudchenko, Goodridge, Seiterle, \& Taube, 1997). In addition, the geometry of a round water tank does not provide good information about the location of the dry platform unless the goal is at the center. Global spatial geometry of the room containing the maze is probably ambiguous in a radial maze because arms point in all directions, and the internal geometry of the maze cannot be used as a cue because the maze is symmetrical. In contrast to the case in these paradigms, our rats found food by traveling back and forth from a fixed home base into a rectangular room, so they could learn about the location of food by learning its relationship to the room's geometry.

Thus, in our experiments, as in a natural environment, place was defined by a set of cues richer than that in other paradigms that have been used to investigate cue competition in spatial learning. Beacon cues apparently interact differently with such richly defined place cues than they do with places defined primarily by distal landmarks. To some extent, the differences may be summarized by saying that - not surprisingly, perhaps-the beacon is a weaker cue in our situation. However, on this account, it is not clear why spatial cues other than the beacon lose control through learned irrelevance in our situation, whereas related examples of cue competition 
between spatial cues seem to reflect direct competition between beacons and landmarks for global predictive value or performance. One possibility is that because our testing room had (to human eyes) rather few conspicuous visual landmarks, information provided by dead reckoning, the geometry of the room, and/or motor responses may have been the primary contributors to place learning. One or more of these may interact with beacons in a different way than landmarks do. For example, beacons and geometry appear to be learned simultaneously without competition (Pearce, Ward-Robinson, Good, Fussell, \& Aydin, 2001). It is clearly important to separate the roles of the individual spatial systems involved in our paradigm. This is an ongoing project beyond the scope of the present article.

The results of some studies from ethology and behavioral neuroscience briefly reviewed earlier have suggested that rather than competing, different kinds of spatial information may be acquired in parallel or be used in a hierarchical manner. Hamsters hoarding food, for example, can home from a novel location by using dead reckoning but preferentially use a familiar landmark if it is available (Etienne, Maurer, \& Seguinot, 1996). Foodcarrying rats show a similar hierarchy of cue use when homing (Maaswinkel \& Whishaw, 1999). Alternatively, researchers have suggested that spatial learning may follow the well-established principles of associative learning, with spatial cues competing for a limited amount of predictive value or associative strength. Another possibility provided by the learning literature is that multiple cues (e.g., place, beacon, motor response) may acquire predictive value but that knowledge about one or more sets of cues is not expressed during testing. A number of studies have indicated that cue competition effects can be explained in terms of such performance deficits, rather than failures of acquisition (e.g., Cole, Barnet, \& Miller, 1995). The approach described here has the potential to further address these issues.

\section{REFERENCES}

Alyan, S., \& JANDER, R. (1994). Short-range homing in the house mouse, Mus musculus: Stages in the learning of directions. Animal Behaviour, 48, 285-298.

Bellingham, W. P., \& Gillette, K. (1981). Attenuation of overshadowing as a function of nondifferential compound conditioning trials. Bulletin of the Psychonomic Society, 18, 218-220.

Benhamou, S., \& Poucet, B. (1998). Landmark use by navigation rats (Rattus norvegicus): Contrasting geometric and featural information. Journal of Comparative Psychology, 112, 317-322.

Biegler, R, \& Morris, R. G. M. (1999). Blocking in the spatial domain with arrays of discrete landmarks. Journal of Experimental Psychology: Animal Behavior Processes, 25, 334-351.

Chapillon, P., \& Roullet, P. (1996). Use of proximal and distal cues in place navigation by mice changes during ontogeny. Developmental Psychobiology, 29, 529-545.

Cheng, K. (1986). A purely geometric module in the rat's spatial representation. Cognition, 23, 149-178.

Cheng, K., \& Spetch, M. L. (1998). Mechanisms of landmark use in mammals and birds. In S. Healy (Ed.), Spatial representation in animals (pp. 1-17). Oxford: Oxford University Press.

Cole, R. P., Barnet, R. C., \& Miller, R. R. (1995). Effect of relative validity: Learning or performance deficit? Journal of Experimental Psychology: Animal Behavior Processes, 21, 293-303.

Diez-Chamizo, V., Sterio, D., \& Mackintosh, N. J. (1985). Blocking and overshadowing between intra-maze and extra-maze cues: A test of the independence of locale and guidance learning. Quarterly Journal of Experimental Psychology, 37B, 235-253.

Dudchenko, P. A., Goodridge, J. P., Seiterle, D. A., \& Taube, J. S. (1997). Effects of repeated disorientation on the acquisition of spatial tasks in rats: Dissociation between the appetitive radial arm maze and aversive water maze. Journal of Experimental Psychology: Animal Behavior Processes, 23, 194-210.

Etienne, A. S., Berlie, J., Georgakopoulos J., \& Maurer, R. (1998). Role of dead reckoning in navigation. In S. Healy (Ed.), Spatial representations in animals (pp. 54-68). Oxford: Oxford University Press.

Etienne, A. S., Maurer, R, \& Seguinot, V. (1996). Path integration in mammals and its interaction with visual landmarks. Journal of Experimental Biology, 199, 201-209.

Gallistel, C. R. (1990). The organization of learning. Cambridge, MA: MIT Press.

Gibson, B. M., Shettleworth, S. J., \& McDonald, R. J. (2001). Finding a goal on dry land and in the water: Differential effects of disorientation on spatial learning. Behavioural Brain Research, 123, 103-111.

KAMIN, L. J. (1969). Predictability, surprise, attention, and conditioning. In B. A. Campbell \& R. M. Church (Eds.), Punishment and aversive behavior (pp. 279-296). New York: Appleton-Century-Crofts.

Lavanex, P., \& Schenk, F. (1995). Influence of local environmental olfactory cues on place learning in rats. Physiology \& Behavior, 58, 1059-1066.

MaAswinkel, H., \& Whishaw, I. Q. (1999). Homing with locale, taxon, and dead reckoning strategies by foraging rats: Sensory hierarchy in spatial navigation. Behavioural Brain Research, 99, 143 152.

Mackintosh, N. J. (1976). Overshadowing and stimulus intensity. Animal Learning \& Behavior, 4, 186-192.

Mackintosh, N. J. (2002). Do not ask whether they have a cognitive map but how they find their way about. Psicologia, 23, 165-185.

March, J., Chamizo, V. D., \& Mackintosh, N. J. (1992). Reciprocal overshadowing between intra-maze and extra-maze cues. Quarterly Journal of Experimental Psychology, 45B, 49-63.

McDonald, R. J., \& White, N. M. (1993). A triple dissociation of memory systems: Hippocampus, amygdala, and dorsal striatum. Behavioral Neuroscience, 107, 3-22.

McDonald, R. J., \& White, N. M. (1994). Parallel information processing in the water maze: Evidence for independent memory systems involving dorsal striatum and hippocampus. Behavioral \& Neural Biology, 61, 260-270.

O'KeEFE, J., \& NADEL, L. (1978). The hippocampus as a cognitive map. Oxford: Oxford University Press, Clarendon Press.

Packard, M. G., \& McGaugh, J. L. (1992). Double dissociation of fornix and caudate lesions on acquisition of two water maze tasks: Further evidence for multiple memory systems. Behavioral Neuroscience, 106, 439-446.

Pavlov, I. P. (1927). Conditioned reflexes (G. V. Anrep, Trans.). London: Oxford University Press.

Pearce, J. M., Roberts, A. D. L., \& Good, M. (1998). Hippocampal lesions disrupt navigation based on cognitive maps but not heading vectors. Nature, 396, 75-77.

Pearce, J. M., Ward-Robinson, J., Good, M., Fussell, C., \& Aydin, A. (2001). Influence of a beacon on spatial learning based on the shape of the test environment. Journal of Experimental Psychology: Animal Behavior Processes, 27, 329-344.

Phelps, M. T., \& Roberts, W. A. (1989). Central-place foraging by Rattus norvegicus on a radial maze. Journal of Comparative Psychology, 103, 326-333.

Redhead, E. S., Roberts, A., Good, M., \& Pearce, J. M. (1997). Interaction between piloting and beacon homing by rats in a swimming pool. Journal of Experimental Psychology: Animal Behavior Processes, 23, 340-350. 
Roberts, A. D. L., \& Pearce, J. M. (1999). Blocking in the Morris swimming pool. Journal of Experimental Psychology: Animal Behavior Processes, 25, 225-235.

Shettleworth, S. J. (1998). Cognition, evolution, and behavior. New York: Oxford University Press.

Steele, R. J., \& Morris, R. G. M. (1999). Delay-dependent impairment of a matching-to-place task with chronic and intrahippocampal infusion of the NMDA-antagonist D-AP5. Hippocampus, 9, 118-136.

Tolman, E. C. (1948). Cognitive maps in rats and men. Psychological Review, 55, 189-208.

Wagner, A. R. Logan, F. A., Haberlandt, K., \& Price, T. (1968). Stimulus selection in animal discrimination learning. Journal of $E x$ perimental Psychology, 76, 171-180.

Whishaw, I. Q., Coles, B. L. K., \& Bellerive, C. H. M. (1995). Food carrying: A new method for naturalistic studies of spontaneous alternation. Journal of Neuroscience Methods, 61, 139-143.
Whishaw, I. Q., \& Gorney, B. (1999). Path integration absent in scenttracking fimbria-fornix rats: Evidence for hippocampal involvement in "sense of direction" and "sense of distance" using self-movement cues. Journal of Neuroscience, 19, 4662-4673.

Whishaw, I. Q., \& Tomie, J.-A. (1989). Food-pellet size modifies the hoarding behavior of foraging rats. Psychobiology, 17, 93-101.

Whishaw, I. Q., \& Tomie, J.-A. (1997). Piloting and dead reckoning dissociated by fimbria-fornix lesions in a rat food carrying task. $B e$ havioural Brain Research, 89, 87-97.

White, N. M., \& MCDonald, R. J. (2002). Multiple parallel memory systems in the brain of the rat. Neurobiology of Learning \& Memory, 77, 125-184.

(Manuscript received June 6, 2002; revision accepted for publication January 9, 2003.) 